Original Research Article

\title{
Effect of ethanolic extract of Vitex negundo leaves on experimentally induced inflammatory bowel disease in albino rats
}

\author{
Shipra Kaushik ${ }^{1 *}$, Harsh Wardhan ${ }^{1}$, Shobhit Kaushik ${ }^{2}$, Vikash Verma ${ }^{1}$
}

${ }^{1}$ Department of Pharmacology, GS Medical College and Hospital, Pilkuwa, Uttar Pradesh, India

${ }^{2}$ Department of Anesthesiology, Assam Medical College and Hospital, Dibrugarh, Assam, India

Received: 20 May 2019

Revised: 10 June 2019

Accepted: 02 July 2019

*Correspondence to:

Dr. Shipra Kaushik,

Email: shipra014@gmail.com

Copyright: (C) the author(s), publisher and licensee Medip Academy. This is an openaccess article distributed under the terms of the Creative Commons Attribution NonCommercial License, which permits unrestricted noncommercial use, distribution, and reproduction in any medium, provided the original work is properly cited.

\begin{abstract}
Background: Ulcerative colitis (UC) and Crohn's disease (CD) are collectively known as inflammatory bowel disease (IBD). Pathophysiology of IBD is not known with certainty. Immunological processes and reactive oxygen species (ROS) have been proposed to contribute considerably to development of tissue injury. Some of the intestinal and/or colonic injury and dysfunction observed in IBD is due to elaboration of these reactive species. Commonly used drugs, in particular sulfasalazine and its active moiety 5-aminosalicylic acid, are potent ROS scavengers. The present study was carried out to evaluate the effect of ethanolic extract of Vitex negundo (EEVN) leaves on experimentally induced inflammatory bowel disease in albino rats.

Methods: The rats were divided into four groups of six animals each. Group A and group B received gum acacia per orally, group $\mathrm{C}$ received EEVN in dose of $500 \mathrm{mg} / \mathrm{kg} /$ day per orally, and group D received 5-amino salicylic acid (5-ASA) in the dose of $100 \mathrm{mg} / \mathrm{kg} /$ day per orally. All the animals were pre-treated with respective drugs (volume of drugs was kept constant at $10 \mathrm{ml} / \mathrm{kg}$ ) for five days, along with the normal diet. On fifth day animals were kept fasting for 12 hours (overnight) and IBD was induced next morning in Groups B, C and D by administration of one $\mathrm{ml}$ of $4 \%$ acetic acid solution transrectally (TR). Group A (normal control) received $0.9 \%$ normal saline transrectally (TR) instead.

Results: The results have been shown that EEVN has significant activity against experimentally induced IBD when compared to the experimental control, with near normalization of colon architecture both macroscopically as well as microscopically. Tissue oxidative stress was reduced with significant improvement in tissue levels of superoxide dismutase (SOD) and catalase (CAT). Also, significant improvement in levels of myeloperoxidase (MPO) was observed.

Conclusions: It is concluded that ethanolic extract of leaves of Vitex negundo has got potent activity against experimentally induced IBD due to its antiinflammatory and anti-oxidant properties.
\end{abstract}

Keywords: Anti-inflammatory, Inflammatory bowel disease, Vitex negundo

\section{INTRODUCTION}

Idiopathic Inflammatory bowel disease (IBD) is a set of chronic inflammatory conditions resulting from inappropriate persistent activation of the mucosal immune system driven by the process of intestinal flora. The two disorders known as IBD are Crohn's disease and Ulcerative colitis. A consensus hypothesis is that in genetically predisposed individuals, both exogenous factors (e.g., normal luminal flora) and host factors (e.g., intestinal epithelial cell barrier function, innate and adaptive immune function) cause a chronic state of dysregulated mucosal immune function that is further modified by specific environmental factors (e.g., smoking). ${ }^{1}$ Despite the fact that a number of theories have been proposed to describe the causative agent in inflammatory bowel disease (IBD), still the etiology of IBD remains unknown. Clinical, epidemiological and 
experimental studies have been used to attempt to elucidate the etiology of IBD. A number of factors, including genetic, microbial, viral, immunological, nutritional, thrombosis and environmental agents have been implicated in the pathogenesis of IBD. ${ }^{2}$

Neutrophil infiltration in the extravascular space involves a complex sequence of interaction between circulating neutrophils and the vascular endothelium, including rolling, adhesion and trans endothelial migration. Myeloperoxidase(MPO) is an enzyme mainly found in azurophilic granules of neutrophils. It is a good marker of neutrophil infiltration in gastrointestinal tissues, as well as inflammation and tissue injury. Besides, significant amounts of superoxide can be generated by a variety of endogenous enzyme systems such as the peroxisomal enzyme xanthine oxidase (XO) following tissue ischemia. $\mathrm{XO}$ activity is often increased in intestinal inflammation through the induction by TNF- $\alpha$ and activated neutrophils. ${ }^{3}$

It has been suggested that $\mathrm{XO}$ is a significant source of superoxide in the inflammation of IBD. ${ }^{4}$ The concentrations of endogenous antioxidants, such as reduced glutathione (GSH), alpha-tocopherol and cysteine, are all significantly decreased in IBD patients. As a result, the balance between antioxidants and ROM becomes seriously impaired. ${ }^{5}$ A population based study performed in India for ulcerative colitis shows a prevalence rate of 44.3 per 100000 inhabitants and an incidence rate of 6.02 cases per 100000 inhabitants. $^{6}$

Vitex negundo is a deciduous aromatic shrub. It chiefly occurs in Pakistan, India and Ceylon. The leaves and roots of the plant is used as medicine, although almost whole of the plant is useful. The decoction of leaves is considered to be a tonic, vermifuge and is given along with long pepper in catarrhal fever. ${ }^{7}$

Water extract of matured fresh leaves exhibited antiinflammatory, analgesic and antihistamine properties. Phytochemical screening studies of $V$. negundo revealed the presence of volatile oil, triterpenes, diterpenes, sesquiterpenes, lignin, flavonoids, flavone glycosides and stilbene derivative. ${ }^{8}$

\section{METHODS}

\section{Animals}

The study was conducted on male and female healthy albino wistar rats weighing 150-250 gm. The animals were obtained from Central animal house, Assam medical college, Dibrugarh. The rats were housed in polypropylene cages and maintained under standard conditions (12 h light/dark cycle, at room temperature $25 \pm 3^{\circ} \mathrm{C}$ and $35-60 \%$ humidity), standard pellet as a basal diet and purified drinking water ad libitum. The study was approved by the Institutional Animal Ethics Committee, AMC. The albino rats were maintained and followed under the Good Laboratory Practices and the guidelines of Committee for the Purpose of Control and Supervision on Experiments on Animals. ${ }^{9}$

\section{Induction of experimental IBD}

For induction of IBD, a soft paediatric catheter was advanced six $\mathrm{cm}$ from the anus under low-dose ether anaesthesia. Rats were in Trendelenburg position during this process and one $\mathrm{ml}$ of $4 \%$ acetic acid or $0.9 \% \mathrm{NS}$ solution was slowly administered TR. The rats were maintained in head-down position for 30 seconds to prevent a leakage, and the rest of the solution was aspirated. After this process, two $\mathrm{ml}$ of phosphate buffer solution with $\mathrm{pH} 7$ was administered TR.

All the animals were sacrificed after 48 hours of IBD induction, by ether overdose. Abdomen was opened and colon was exposed. Distal eight $\mathrm{cm}$ of colon was excised and opened by a longitudinal incision. After washing the mucosa with saline solution, mucosal injury was assessed macroscopically using scale of Morris et al. ${ }^{10-11}$ Disease activity index (DAI) was also measured, the ratio of colon weight to body weight, which was used as a parameter to assess the degree of tissue oedema and reflects the severity of colonic inflammation.

A 6 to $8 \mathrm{~mm}$ sample block of the inflamed colonic tissue with the full thickness was excised from a region of grossly visible damage for histological analysis. Formalin fixed tissue samples were embedded in paraffin and stained with Haematoxylin and Eosin stain. Colonic tissues were scored for histological damage using the criteria of Wallace and Keenan. After scoring colonic tissue samples were homogenized with 10 volumes of ice-cold $0.25 \mathrm{M}$ sucrose, centrifuged at $14000 \mathrm{rpm}$ to measure the biochemical parameters in resulting supernatant. ${ }^{3}$

\section{Biochemical assessments}

Myeloperoxidase (MPO) activity, Superoxide dismutase (SOD) level, Catalase level. The above parameters were measured using Double beam UV Spectrophotometer. ${ }^{12-13}$

\section{Preparation of plant extract}

Fresh leaves of Vitex negundo were collected from Assam Medical College Campus, Dibrugarh. The leaves were separated and air-dried, which were then crushed and powdered. Ethanol extract was prepared by percolation method followed by steam evaporation.

\section{Acute oral toxicity test in rats}

After an overnight fasting of rats, EEVN was given orally in doses of 50,100,200,500 and maximum dose of 1000 $\mathrm{mg} / \mathrm{Kg}$ body weight and observed carefully for the first 2$3 \mathrm{hr}$ for signs of toxicity. The behavioral changes and \% mortality were documented beginning with $24 \mathrm{~h}$ up to a period of 14 days. $^{14}$ 


\section{Experimental design}

Twenty four (24) healthy Wistar albino rats weighing 150200 grams were used in the study and divided into four groups with six animals in each group as follows:

- Group A(normal control): $3 \%$ gum acacia 10 $\mathrm{ml} / \mathrm{kg} / \mathrm{day}$, p.o.

- Group B(experimental control): $3 \%$ gum acacia 10 $\mathrm{ml} / \mathrm{kg} / \mathrm{day}$, p.o. with of one $\mathrm{ml}$ of $4 \%$ acetic acid

- Group C(test): Vitex negundo extract $500 \mathrm{mg} / \mathrm{kg} / \mathrm{day}$ p.o.

- Group D(standard): 5-aminosalicylic(5-ASA) acid $100 \mathrm{mg} / \mathrm{kg} /$ day p.o.

All the animals were pre-treated with respective drugs (volume of drugs was kept constant at $10 \mathrm{ml} / \mathrm{kg}$ ) for five days, along with the normal diet. On fifth day animals were kept fasting for 12 hours (overnight) and IBD was induced next morning in Groups B, C and D by administration of one $\mathrm{ml}$ of $4 \%$ acetic acid solution transrectally (TR). Group A (normal control) received $0.9 \%$ normal saline (transrectally) instead.

\section{Statistical analysis}

Data were calculated as mean \pm standard error of mean (SEM). Statistical analysis was performed using SPSS (IBM SPSS Statistics Version 20.0). The values were analyzed using one way Analysis of Variance (ANOVA), followed by post hoc Dunnett's multiple comparison tests.
The results were considered to be significant when $\mathrm{p}$ values were less than $0.05(\mathrm{p}<0.05)$.

\section{RESULTS}

\section{Acute toxicity study}

Acute Toxicity Study showed that no signs of toxicity, behavioral changes and mortality were there up to a dose of $1000 \mathrm{mg} / \mathrm{kg}$ body weight of the ATE.

\section{Effect on IBD induced Rats}

\section{Normal control (group A)}

Group A, normal control showed normal mucosal architecture macroscopically and microscopically (Table 1, Figure $1 \mathrm{~A})$.

\section{Acetic acid (group B)}

Acetic acid administration to the experimental control group caused significant macroscopic ulcerations and inflammations in rat colon along with significant mucosal injury microscopically, when compared to the normal control group $(p<0.05)$. Also, there was significant derangement of biochemical parameters including tissue levels of MPO, SOD and catalase $(p<0.05)$ showing oxidative stress due to colon damage and colonic inflammation (Table 1, Figure 1 B, Figure 2).

Table 1: Effect of Vitex negundo (L) on experimentally induced IBD in rats.

\begin{tabular}{|lllllll|} 
Groups & $\begin{array}{l}\text { Macroscopic } \\
\text { score }\end{array}$ & $\begin{array}{l}\text { Disease } \\
\text { activity index } \\
\text { (DAI) }\end{array}$ & $\begin{array}{l}\text { Microscopic } \\
\text { score }\end{array}$ & $\begin{array}{l}\text { Tissue CAT } \\
(\mu \text { mol/min/m } \\
\text { g of proteins) }\end{array}$ & $\begin{array}{l}\text { Tissue SOD } \\
\text { (U/mg of } \\
\text { proteins) }\end{array}$ & $\begin{array}{l}\text { Tissue } \\
\text { MPO(U/g) }\end{array}$ \\
\hline A (Normal control) & $0.33 \pm 0.21^{\mathrm{a}, \mathrm{d}}$ & $0.67 \pm 0.042^{\mathrm{a}, \mathrm{d}}$ & $0 \pm 0^{\mathrm{a}, \mathrm{c}}$ & $376.2 \pm 6.13^{\mathrm{a}, \mathrm{c}}$ & $6.9 \pm 0.33^{\mathrm{a}, \mathrm{c}}$ & $0.33 \pm 0.03^{\mathrm{a}, \mathrm{c}}$ \\
\hline $\mathrm{B}$ (Exp. Control) & $4.67 \pm 0.21^{\mathrm{c}}$ & $1.14 \pm 0.045^{\mathrm{c}}$ & $4.7 \pm 0.21^{\mathrm{c}}$ & $109.5 \pm 5.16^{\mathrm{c}}$ & $3.4 \pm 0.24^{\mathrm{c}}$ & $2.9 \pm 0.06^{\mathrm{c}}$ \\
\hline $\mathrm{C}$ (EEVN) & $2.0 \pm 0.36^{\mathrm{a}, \mathrm{c}}$ & $0.89 \pm 0.003^{\mathrm{a}, \mathrm{c}}$ & $3.0 \pm 0.36^{\mathrm{a}, \mathrm{c}}$ & $176.4 \pm 7.67^{\mathrm{a}, \mathrm{c}}$ & $5.2 \pm 0.32^{\mathrm{a}, \mathrm{c}}$ & $1.33 \pm 0.07^{\mathrm{a}, \mathrm{c}}$ \\
\hline $\mathrm{D}(5-\mathrm{ASA})$ & $1.0 \pm 0.26^{\mathrm{a}}$ & $0.76 \pm 0.033^{\mathrm{a}}$ & $1.5 \pm 0.22^{\mathrm{a}}$ & $304.9 \pm 9.23^{\mathrm{a}}$ & $6.4 \pm 0.27^{\mathrm{a}}$ & $0.76 \pm 0.033^{\mathrm{a}}$ \\
\hline $\mathrm{A}^{\mathrm{F}}$ & 50.26 & 28.29 & 70.37 & 250.8 & 28.44 & 333.4 \\
\hline $\mathrm{N}^{\mathrm{df}} \mathrm{O}$ & 20,3 & 20,3 & 20,3 & 20,3 & 20,3 & 20,3 \\
\hline $\mathrm{V}^{\mathrm{P}} \mathrm{A}$ & $<0.05$ & $<0.05$ & $<0.05$ & $<0.05$ & $<0.05$ & $<0.05$ \\
\hline
\end{tabular}

Values expressed as mean \pm SEM, $n=6$, a-p $<0.05$ and $b-p>0.05$ when compared to experimental control; c-p $<0.05$ and $d-p>0.05$ when compared to 5-ASA; ANOVA followed by Dunnet's t-test.

\section{Acetic acid (group B)}

Acetic acid administration to the experimental control group caused significant macroscopic ulcerations and inflammations in rat colon along with significant mucosal injury microscopically, when compared to the normal control group $(\mathrm{p}<0.05)$. Also, there was significant derangement of biochemical parameters including tissue levels of MPO, SOD and catalase $(\mathrm{p}<0.05)$ showing oxidative stress due to colon damage and colonic inflammation (Table 1, Figure 1 B, Figure 2).

\section{EEVN (group C)}

EEVN showed significant activity against experimentally induced IBD when compared to the experimental control ( $\mathrm{p}<0.05$ ) with near normalization of colon architecture both macroscopically as well as microscopically. Tissue oxidative stress was reduced with significant improvement in tissue levels of SOD and CAT ( $p<0.05)$. Also, significant improvement in levels of MPO was observed $(\mathrm{p}<0.05)$ (Table 1, Figure C, Figure 2). 


\section{5-ASA (Group D)}

As for the standard drug 5-ASA, its activity against IBD was significantly greater than EEVN with regard to all parameters $(\mathrm{p}<0.05)$.

When compared to the normal control, 5-ASA showed near normalization of DAI and macroscopic score, as there was no significant difference between normal control group and 5-ASA group ( $\mathrm{p}>0.05$ ) (Table 1, Figure D, Figure 2).

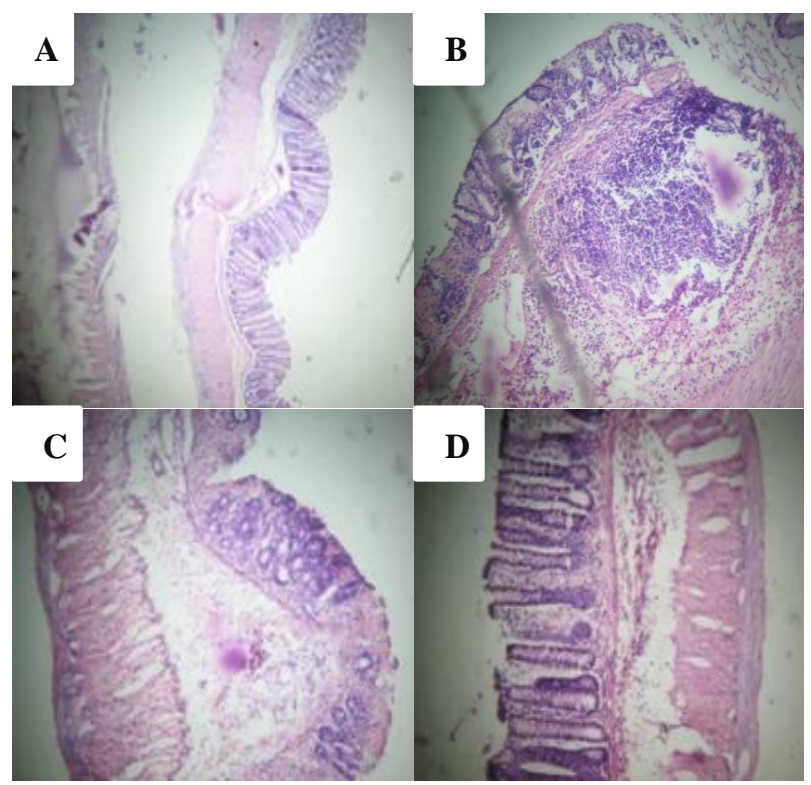

(A): Normal control (Normal mucosal architecture), (B): Experimental control (Extensive necrosis and transmural infiltration), (C): Test (Infiltration upto submucosa, architecture maintained), (D): 5-ASA (Near normalization of architecture with mucosal infiltration only)

Figure 1: Effect of Vitex negundo (L) on experimentally induced IBD in rats.

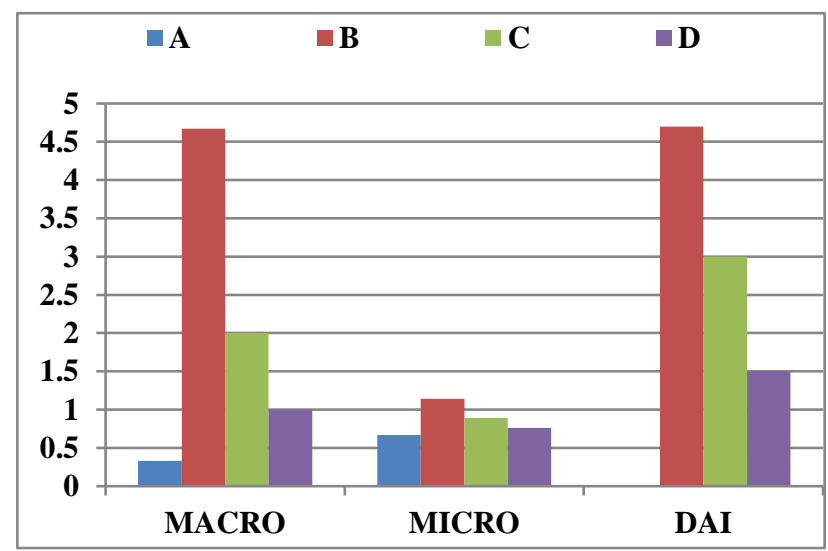

Figure 2: Bar diagram showing macroscopic, microscopic and disease activity index of the four groups A, B, C and D.

\section{DISCUSSION}

IBD is a chronic intestinal condition with dysregulated mucosal immune function. Two major types are UC and $\mathrm{CD}$. UC is a mucosal disease that usually involves the rectum and extends proximally to involve the colon manifesting with diarrhea, rectal bleeding, tenesmus, passage of mucus and crampy abdominal pain. ${ }^{15}$ The results showed that ethanolic extract of leaves of Vitex negundo has got a good potential to suppress experimental colitis in rats, as indicated by macroscopic, microscopic and biochemical evaluations. All parts of the plant from root to fruit possess a multitude of phytochemical secondary metabolites, which impart an unprecedented variety of medicinal uses to the plant. Vitex negundo has been investigated for antipyretic, analgesic, antiinflammatory, anticonvulsant, hepatoprotective and bronchial relaxant. ${ }^{16}$

Acetic acid-induced colitis model is similar to human ulcerative colitis in terms of histological features. It affects the distal colon portion and induces non-transmural inflammation, massive necrosis of mucosal and sub mucosal layers, mucosal oedema, and neutrophil infiltration of the mucosa and sub mucosal ulceration. The protonated form of the acid liberates protons within the intracellular space and causes a massive intracellular acidification resulting in massive epithelial damage. Inflammation is the pathogenesis of IBD and several pathways are associated with inflammatory response in IBD. The inflammatory response initiated by acetic acid includes activation of cyclooxygenase and lipoxygenase pathways. ${ }^{17}$

A key factor involved in the pathogenesis of IBD is oxidative stress. ${ }^{18}$ Intestinal mucosal damage that occurs in IBD, is related to both increased free radical production and a low concentration of endogenous antioxidant defense. ${ }^{19}$

\section{CONCLUSION}

As proved by the above study and also described in literature, leaves extract of Vitex negundo possesses significant anti-oxidant property, proving its role in the management of experimentally induced IBD. Hence it can be concluded from the said study that ethanol extract of leaves of Vitex negundo has got potent activity against experimentally induced IBD due to its anti-inflammatory and anti-oxidant properties, still it is to be further investigated for its clinical utility.

\section{ACKNOWLEDGEMENTS}

The authors wish to thank lab attendants of department of pharmacology, Assam medical college, Dibrugarh, India for supporting to carry out this study.

Funding: No funding sources

Conflict of interest: None declared

Ethical approval: The study was approved by the Institutional Animal Ethics Committee 


\section{REFERENCES}

1. Daniel H. Lowenstein, Diseases of the Central Nevous System. Seizures and Epilepsy. In : Kasper, Hauser, Fauci, Jameson, Longo and Loscalzo, eds. Harrison's Principles of Internal Medicine. $19^{\text {th }}$ ed. New York, NY: Mc Graw-Hill, Inc; 2015: 1947-1964.

2. Gottfried IS, Nash HR, Devlin EW. Presence of Novel Forms in the Colon of Inflammatory Bowel Disease Patients. The Am J Gastroenterol. 1999 Feb;94(2):537-9.

3. Ko JK, Lam FY, Cheung AP. Amelioration of experimental colitis by Astragalus membranaceus through anti-oxidation and inhibition of adhesion molecule synthesis. World J Gastroenterol. 2005;11(37):5787-94.

4. Simmonds NJ, Rampton DS. Inflammatory bowel disease--a radical view. Gut. 1993 Jul;34(7):865-8.

5. Ramakrishna BS, Varghese R, Jayakumar S, Mathan $\mathrm{M}$, Balasubramanian KA. Circulating antioxidants in ulcerative colitis and their relationship to disease severity and activity. J Gastroenterol Hepatol. 1997 Jul;12(7):490-4.

6. Sood A, Midha V, Sood N, Bhatia AS, Avasthi G. Incidence and prevalence of ulcerative colitis in Punjab, North India. Gut. 2003 Nov 1;52(11):1587-90.

7. Chopra RN, Nayer SL, Chopra IC . Acacia catechu Wild. Glossary of Indian Medicinal plants. Council of Scientific and Industrial Research. New Delhi, India;1956-1965:12.

8. Dr. Xiaorui Zhang. Introduction. WHO monographs on selected medicinal plants. $1^{\text {st }}$ Indian ed. Vol 1. NewDelhi: A.I.T.B.S. Publishers \& Distributers; 2005: 5-8.

9. CPCSEA (Committee for the Purpose of Control and Supervision on Experiments on Animals). CPCSEA guidelines for laboratory animal facility. Indian $\mathbf{J}$ Pharmacol. 2003;35:257-74.

10. Zeytunlu M, Korkut M, Akgün E, Firat O, Aynaci M, Içöz G, Kiliç M, Ersin S, Özütemiz Ö. The comparative effects of calcium channel blockers in an experimental colitis model in rats. Turk $\mathbf{J}$ Gastroenterol. 2004;15(4):243-9.
11. Morris GP, Beck PL, Herrigge MS, Depew WT, Szewcdzuk MR, Wallace JL. Hapten induced model of chronic inflammation and ulceration in the rat colon. Gastroenterology. 1989;96:795-803.

12. Beers RF Jr, Sizer IW. A spectrophotometric method for measuring the breakdown of hydrogen peroxide by catalase. J Biol Chem. 1952;195:133-40.

13. Krawizs JE. Quantitative assay for acute intestinal inflammation based on myeloperoxidase activity. Gastroenterology. 1984;87:1344-50.

14. OECD/OCDE. 425 guideline. OECD guidelines for testing of chemicals. Acute Oral Toxicity-Up-andDown-Procedure; 2005:1-26.

15. 15. Friedman S, Blumberg S. Inflammatory bowel disease. In: Kasper DL, Braunwald U, Fauci AS, Hauser SL, Longo DL, Jameson JL, editors. Harrison's Principles of Internal medicine, $18^{\text {th }}$ ed, McGraw-Hill; 2012: 1776-1788.

16. Gandigawad P, Hodlur N, Sori RK, Poojar B, Tilak A, Korade RA. Evaluation of analgesic activity of sodium valproate and ethanolic extract of vitex negundo in experimental analgesic models in wistar rats. Int $\mathrm{J}$ Basic Clin Pharmacol. 2018;7:2036-41.

17. Dutta S, Das S. Effect of the leaves of Psidium guajava Linn. on experimentally induced colitis in animal models. International Journal of Green Pharmacy. 2011;5(1):55-60.

18. Grisham MB, Granger DN. Neutrophil-mediated mucosal injury. Digestive Dis Sci. 1988 Mar $1 ; 33(3): 6 \mathrm{~S}-15 \mathrm{~S}$

19. Shivashankar P, Purushotham K, Lahkar M. Effect of Alternanthera brasiliana in experimentally induced inflammatory bowel disease in albino rats. Int J Basic Clin Pharmacol. 2016;5:1809-15.

Cite this article as: Kaushik S, Wardhan H, Kaushik $\mathrm{S}$, Verma V. Effect of ethanolic extract of Vitex negundo leaves on experimentally induced inflammatory bowel disease in albino rats. Int $\mathrm{J}$ Basic Clin Pharmacol 2019;8:1800-4. 